1. M.B.B.S., MCPS, M Phil, PhD Professor and Head of Physiology, Liaquat National Medical College \& Hospital, Karachi

2. M.B.B.S

Lecturer, Dept. of Physiology, Liaquat National Medical College \& Hospital, Karachi

3. M.B.B.S., M Phil

Assistant Professor, Dept. of Physiology, Liaquat National Medical College \& Hospital, Karach

Correspondence Address: Prof. Dr. S. Hafeez ul Hassan Head of Department of Physiology, Liaquat National Medical College \& Hospital.

Stadium Road, Karachi, Pakistan. dr_hafeez@hotmail.com

Article received on: $16 / 05 / 2015$

Accepted for publication: 02/10/2015

Received after proof reading: $13 / 11 / 2015$

\section{BRONCHIAL ASTHMA; DURATION OF ASTHMA IS NOT CORRELATED WITH TOTAL ANTI OXIDANT CAPACITY AND LUNG FUNCTION PARAMETERS}

\author{
Dr Syed Hafeezul Hassan', Dr Javeria Rehman², Dr Ahsan Ashfaq ${ }^{3}$
}

ABSTRACT... Asthma is a chronic inflammatory disorder of the airways, which is associated with excessive airway narrowing in response to stimuli that have little or no effect on healthy subjects. Airway hyper-responsiveness with a short duration of asthma is coupled with airway inflammation which may or may not be associated with lung impairment. Objectives: To study correlation of asthma duration with total anti oxidant capacity and lung function parameters. Design: Cross sectional study. Period: June 2013 to Dec 2013. Setting: Baqai Medical University and Hospital. Methodology: A total of 92 known and diagnosed cases of asthma meeting the inclusion criteria were recruited in the study. The subjects included both male and female with age ranging from 16-70 years. Portable handheld electronic Spirometer was used for performing spirometry. FRAP assay was done to measure TAC according to the method of Benzie and Strai. Results: The mean age of patients ( $n-92)$ was $34.88 \pm 12.14$ SD. The mean duration of asthma was $11.57 \pm 11.30 \mathrm{SD}$ years. Mean value of TAC was found to be 11.46 \pm 4.34SD. Mean FEV, was 1.90 $\pm 0.82 S D$, mean FVC was $2.17 \pm 0.88 \mathrm{SD}$, mean PEFR was 247.8 \pm 122.7 SD and mean $\mathrm{FEV}_{1} / \mathrm{FVC}$ was 86.21 $\pm 16.58 \mathrm{SD}$. Paired sample $\mathrm{t}$ - test was applied to compare the spirometric values which were found highly significant. Pearson correlation was applied and showed negative but insignificant correlation of asthma duration with patients' FEV1, FEV1/FVC and PEFR as well as insignificant correlation with other spirometric parameters and TAC. Conclusion: Our study showed that duration of asthma has no significant correlation with lung function parameters and antioxidant capacity.

Key words: $\quad$ asthma duration, TAC, lung function parameters.

Article Citation: Hassan SH, Rehman J, Ashfaq A. Bronchial asthma; duration of asthma is not correlated with total anti oxidant capacity and lung function parameters. Professional Med J 2015;22(11):1449-1453. DOI: 10.17957/TPMJ/15.2937

\section{INTRODUCTION}

Asthma is characterized by chronic inflammation of the airways, associated with excessive narrowing and airway hyper responsiveness (AHR) to a stimulus that has little or no effect on otherwise healthy subjects. ${ }^{1}$ This particular pattern of airway inflammation induces airway smooth muscle (ASM) hypertrophy as well as hyperplasia due to its increased sensitivity to broncho constrictor stimuli along with increased production and secretion of mucous. ${ }^{2}$ Recurrent episodes of breathlessness, cough and wheeze especially at night and in early morning are the major symptoms of AHR. ${ }^{3}$ These symptoms are usually associated with increased obstruction to airflow within the lung but with treatment can be reversible. ${ }^{4}$

Asthma is usually diagnosed on the basis of its typical symptoms. The reversal in the abnormali- ties of the lung function parameters, greatly augment the diagnostic confidence. Among various available methods, peak expiratory flow rate and spirometry are most commonly prevalent and recognized to evaluate the airflow limitation in asthma. The measurement of forced expiratory volume in first second $\left(\mathrm{FEV}_{1}\right)$ and forced vital capacity (FVC) and peak expiratory flow (PEF) are particularly important in this regard. ${ }^{5}$

In case of asthma the characteristic feature of chronic inflammation is the production of excess of free radicals. It has been proven that as a result of normal physiological processes and environmental interactions the cells are exposed to oxidative stress, however, there exists a complex anti oxidant defense system that plays a vital role in protecting against the potential oxidative damage. ${ }^{6}$ The disturbed oxidant/antioxidant equilibri- 
um in patients with asthma is meant to be restored by antioxidants that are lower in asthmatics. ${ }^{7}$

The exact and actual assessment of oxidative stress is still considered as a problem by the investigators involved in determining the role of free radical damage in disease. Low total antioxidant capacity could be a sign of oxidative stress, thereby parting the cell vulnerable to oxidative damage. The idea of one such investigation that might reveal total antioxidant capacity (TAC) is appreciated. ${ }^{8}$ Due to interactions that occur in vivo among different antioxidant compounds, the protective efficiency of blood cannot be reflected by any one component of anti oxidant complex. Total antioxidant capacity (TAC) considers the cumulative effect of all antioxidants present in blood and body fluids and can, therefore, reflect the accurate antioxidant capacity. ${ }^{9,10}$

Asthma duration is associated with lower lung function, increased asthma symptoms and amplified use of as-needed bronchodilators. These are all measures of asthma severity. It was shown that associations between asthma duration and the spirometric measurements were stronger before as compared to after bronchodilator use. ${ }^{11}$ Airway hyper-responsiveness with a shorter duration of asthma is coupled with airway inflammation which may or may not be associated with lung impairment, whereas with a longer duration, it is suggested to be associated with impaired lung function. ${ }^{12}$ Therefore it was proposed to study the correlation of asthma duration with the lung function parameters and TAC in a set of patients from local population.

\section{MATERIALS AND METHODS}

A total of 92 cases of both genders with age range between 16-70 years who presented as known asthmatics with dyspnoea or subsequently diagnosed on spirometry, without any co morbid, were evaluated and included in the study. Other causes of dyspnoea including cardiac failure, pulmonary fibrosis, anemia, pleural effusion, pneumonia, pneumothorax, and patients with functional cause were excluded from the study based on history, clinical examination and relevant investigations such as complete blood count, arterial blood gases, blood urea nitrogen electrocardiogram, chest x-ray.

\section{MATERIALS}

Portable handheld electronic Spirometer was used for performing spirometry. $5 \mathrm{ml}$ of blood was drawn and transferred in heparin tube, mixed and centrifuged and frozen at -20 Celsius for estimation of total antioxidant capacity. FRAP assay was done to measure TAC according to the method of Benzie and Strain.

Statistical analysis was done by using SPSS 21. Descriptive values were analyzed for mean and standard deviations and Pearson correlation was applied to determine the effect of duration of asthma on outcomes assessed by spirometry and measurement of TAC. $P$ value of $<0.05$ was considered significant.

\section{RESULTS}

The mean age of patients $(\mathrm{N}-92)$ was $34.88 \pm 12.14$ $\mathrm{SD}$. The mean duration of asthma was 11.57 \pm 11.30 SD years. All patients $(\mathrm{N}=92)$ were analyzed for TAC that was found to be ranging from 6.40 to $24.80 \mathrm{~m} \mathrm{~mol} / \mathrm{dl}$ with the mean value of $11.46 \pm 4.34$ SD. (Table-l)

\begin{tabular}{|c|c|c|}
\hline Patient & Range & Mean \pm SD \\
\hline Age(years) & $16-67$ & $34.88 \pm 12.14$ \\
\hline Duration of asthma (years) & $1-48$ & $11.57 \pm 11.30$ \\
\hline TAC (m mol/dl) & $6.40-24.80$ & $11.46 \pm 4.34$ \\
\hline Table-I. Age, duration of asthma, TAC
\end{tabular}

Predicted Spiro metric values were calculated for each individual using spirometry calculator. Mean predicted FEV, was $3.01 \pm 0.63 \mathrm{SD}$, mean predicted FVC was $3.54 \pm 0.78 \mathrm{SD}$, mean predicted PEFR was $435.54 \pm 79.75$ SD and mean predicted $\mathrm{FEV}_{1} / \mathrm{FVC}$ was $81.69 \pm 2.39 \mathrm{SD}$.

The patients were subjected to spirometry. Mean $F E V$, was $1.90 \pm 0.82 S D$, mean FVC was $2.17 \pm 0.88$ SD, mean PEFR was $247.8 \pm 122.7$ SD and mean $\mathrm{FEV}_{1} / \mathrm{FVC}$ was $86.21 \pm 16.58 \mathrm{SD}$. Paired sample $\mathrm{t}$ - test was applied to compare the spirometric values which were found highly significant (Table-II) 


\begin{tabular}{|c|c|c|c|c|}
\hline Patient & Range & $\begin{array}{c}\text { Actual values } \\
\text { Mean } \mathbf{S D}\end{array}$ & $\begin{array}{c}\text { Predicted values } \\
\text { Mean } \pm \text { SD }\end{array}$ & P value (<0.05) \\
\hline FEV1 (L) & $0.40-3.91$ & $1.90 \pm 0.82$ & $3.01 \pm 0.63$ & $<0.01$ \\
\hline FVC (L) & $0.42-5.33$ & $2.17 \pm 0.88$ & $3.54 \pm 0.78$ & $<0.01$ \\
\hline FEV1/FVC (\%) & $1-100$ & $86.21 \pm 16.58$ & $81.69 \pm 2.39$ & 0.01 \\
\hline PEFR (L/m) & $4-595$ & $247.8 \pm 122.7$ & $435.54 \pm 9.75$ & $<0.01$ \\
\hline
\end{tabular}

Table-II. FEV1, FVC, FEV1/FVC and PEFR ( $n=92)$

Pearson correlation was applied and showed negative but insignificant correlation of asthma duration with patients' FEV1, FEV1/FVC and PEFR as well as insignificant correlation with other spirometric parameters and TAC. (Table-III)

\begin{tabular}{|c|c|c|}
\hline Variables & $\begin{array}{c}\text { Correlation } \\
\text { coefficient }(\mathbf{r})\end{array}$ & $\begin{array}{c}\text { P-value } \\
\mathbf{( < 0 . 0 5 )}\end{array}$ \\
\hline TAC $(\mathrm{m} \mathrm{mol} / \mathrm{dl})$ & 0.125 & 0.233 \\
\hline FEV1(L) & -0.005 & 0.961 \\
\hline FVC $(\mathrm{L})$ & 0.027 & 0.800 \\
\hline FEV1/FVC (\%) & -0.063 & 0.550 \\
\hline PEFR (L/m) & -0.090 & 0.393 \\
\hline
\end{tabular}

Table-III. Pearson correlation of asthma duration with TAC and lung function parameters

\section{DISCUSSIONS}

Asthma is a chronic disorder that has no permanent cure. Spirometry is the gold standard in diagnosis and management of asthma.

Air-way injury and repair is a major feature of chronic inflammation occurring in asthma and is proposed to be the main target of asthma treatments. The remodeling process is also affected by the treatment particularly if prescribed in therapeutic doses and for a sufficient duration of time. ${ }^{13}$ In our study the values of spirometric readings were recorded in patients, compared with their predicted values and were found to be significantly reduced.

Oxidative stress is found to be a major feature of asthma therefore, one of the aims of therapy is directed towards the control of disease by prevention and reduction in lung impairment and the risks involved. ${ }^{14}$ There have been many advances in medical and therapeutic sciences that led to a proposition to detect alterations in antioxidant profiles of spirometry proven asthmatics in an attempt to prevent the worsening of asthma symptoms. Hence, early treatment is found to be the most effective strategy for managing asthma exacerbations. ${ }^{15}$ According to Dut et al it was shown that asthma is related to a very strong systemic oxidative stress that amplifies with the progression and severity of the disease. ${ }^{16}$ However, our study shows that the oxidative stress does not depend or increase with the duration of asthma.

According to Taylor et al the achievement of control of the disease manifestation and its progression usually affects the treatment decisions. Similarly, the extent to which the manifestations of asthma have been removed or reduced with treatment is referred as "Asthma control". The status of current clinical control as well as potential risk assessment is the main determinant of disease progression and patient's assessment. ${ }^{17}$ In our study the possible explanation for duration not significantly affecting the oxidative stress and lung function is the implication of recent and advance treatment modalities directed towards asthma control in patients with spirometry proven mild to moderate asthma.

In contrast to our study, a considerable association between alterations in pulmonary function and the duration of asthma was suggested by some studies. ${ }^{18}$ Furthermore, the patients with asthma of short duration were able to achieve normal airflow after bronchodilator administration as compared to those elderly subjects with longstanding asthma. Also study by Cassino et al confirms and extends previous observations suggesting that distal airways or parenchymal remodeling are involved in irreversible airway changes caused by longstanding asthma. It also 
suggested that the severe alterations in pulmonary function may become irreversible with longterm asthma. A number of cross-sectional studies have shown association between duration of asthma with poor levels of lung function s. ${ }^{19}$ Some other workers found that reduced lung function may be associated with childhood asthma, and decline in lung function may also develop in adult asthmatics during their life. ${ }^{20,21}$ In agreement to our observation yet another study suggested that in asthma ASM layer thickness is increased and is related to the severity of the disease but not its duration. ${ }^{22}$

Jenkins and Henry in their study showed that the specific airway conductance (sGaw) percent predicted, $\mathrm{FEV}_{1}$ percent predicted and $\mathrm{FEV}_{1} /$ FVC ratio are the measures of association between duration of asthma and airflow limitation. Several parameters of disease severity are associated with duration of disease in adults with childhood-onset asthma. sGaw, $\mathrm{FEV}_{1}$, and $\mathrm{FEV}_{1} /$ FVC ratio were specifically found to be inversely proportional to asthma duration. Hence for children and adults with childhood onset asthma, the duration of asthma remained considerably associated with changes in lung function. ${ }^{23}$ This was in contradiction to our study. However, the same study suggested that at the time or very soon after the preliminary diagnosis of asthma is made, significant compromise in lung function occurred in patients with onset of asthma in adult hood. It also stated that adults with childhood-onset asthma, who have the longest duration of asthma, did not display the greatest impairment in lung function suggesting that disease duration should not be an important contributor to disease severity in all adults with asthma. Our study results are consistent with this study to an extent that in adults the duration of asthma is associated inversely with FEV1/FVC and PEFR but is not significant. This observation is in agreement with Burrows et al who stated a decline in lung function, soon after the diagnosis, is demonstrated in patients with adult-onset asthma which is later followed by comparatively stable lung function with subsequent treatment. ${ }^{24}$

\section{CONCLUSIONS}

In our study it was found that duration of asthma has no significant correlation with lung function parameters and total antioxidant capacity.

Copyright @ 02 Oct, 2015.

\section{REFERENCES}

1. Pelligrino R, Violante $B$ and Brusasco V. Maximal broncho constriction in humans: relationship to deep inhalation and airway sensitivity. Am J Respir Crit.Care Med 1996; 153:115-121?

2. Catarina B, Kazohiro I, Peter JB and Sergei AK. Differential Flow analysis of Exhaled Nitric Oxide in Patients with asthma of differing severity. Chest 2007; 131:1353-62.

3. Murray C, lan W, Tom T and Chee KC. Acute asthma. Oxford handbook of acute medicine 2007; 7:164-67.

4. Global initiative for asthma Gina executive committee. Global strategy for asthma management and prevention. 2006 update.www.ginasthma.org

5. Global initiative for asthma Gina executive committee. Global strategy for asthma management and prevention. 2008 update.www.ginasthma.org.

6. Ercan H, Birben E, Dizdar EA, Keskin O, Karaaslan C, Soyer OU, Dut R, Sackesen C, Besler T and Kalayci O. Oxidative stress and genetic and epidemiologic determinants of oxidant injury in childhood asthma. $J$ Allergy Clin Immunol 2006; 118(5):1097-104.

7. Oberholzer H.M, Pretorius E. The role of vitamins and minerals in the alleviation of asthma symptoms. Early Child Development and Care 2010; (180)7:913920.

8. Young IS and Woodside JV. Antioxidants in health and disease. J Clin Pathol 2001; 54:176-186.

9. Nagy G, Ward J, Mosser DD, Koncz A, Gergely P Jr, Stancato C, Qian Y, Fernandez D, Niland B, Grossman $\mathrm{CE}$, Telarico T, Banki K and Perl A. Regulation of CD4 Expression via Recycling by HRES-1/RAB4 Controls Susceptibility to HIV Infection. J Biol Chem 2006; 281(45):34574-34591.

10. Suresh V, Annam, Pratibha K and Maruti P. Total antioxidant capacity - a novel early bio-chemical marker of oxidative stress in HIV infected individuals. J Biomed Sci 2009; 16: 16-61.

11. Relationships between duration of asthma and asthma severity among children in the Childhood Asthma Management Program (CAMP)Zeiger, Robert S. et al.Journal of Allergy and Clinical Immunology, Volume 
103 , Issue $3,376-386$.

12. Gronke L, Kanniess F, Holz O,et al. The relationship between airway hyper-responsiveness, markers of inflammation and lung function depends on the duration of the asthmatic disease. Clin Exp Allergy.2002; 32: 57-63.

13. Hoshino M. Impact of inhaled corticosteroids and leukotriene receptor antagonists on airway remodeling. Clin Rev Allergy Immunol 2004; 27:59-64.

14. National Heart Lung and Blood Institute. National Asthma Education and Prevention Program. Expert panel report 3: Guidelines for the diagnosis and management of asthma. 2007.

15. Pollart SM, Compton RM, Elward KS. "Management of acute asthma exacerbations." Am Fam Physician. 2011; 84(1):49-50.

16. Dut, R., et al. "Oxidative stress and its determinants in the airways of children with asthma." Allergy 2008; 63(12):1605-1609.

17. Taylor, D. R., et al. "A new perspective on concepts of asthma severity and control." European Respiratory Journal 2008; 32(3): 545-554.

18. Cassino C, Berger KI, Goldring RM, Norman RG, Kammerman S, Ciotoli $\mathrm{C}$, et al. Duration of asthma and physiologic outcomes in elderly nonsmokers. Am J Respir Crit Care Med 2000; 162(4 Pt 1):1423-1428.

19. Olaguibel Rivera JM, Alvarez-Puebla MJ, Puy Uribe San Martín M, Tallens Armand ML. Duration of asthma and lung function in life-long nonsmoking adults. J Investig Allergol Clin Immunol 2007; 17:236-241.

20. Porpodis K, Papakosta D, Manika K, Kontakiotis T, Gaga $M$, Sichletidis $L$, et al. Long-term prognosis of asthma is good--a 12-year follow-up study. Influence of treatment. J Asthma 2009; 46:625-631.

21. Limb SL, Brown KC, Wood RA, Wise RA, Eggleston PA, Tonascia J, et al. Irreversible lung function deficits in young adults with a history of childhood asthma. $\mathrm{J}$ Allergy Clin Immunol 2005; 116:1213-1219.

22. James, Alan L., et al. "Airway smooth muscle thickness in asthma is related to severity but not duration of asthma." European Respiratory Journal 2009; 34(5):1040-1045.

23. Jenkins, Henry A., et al. "A comparison of the clinical characteristics of children and adults with severe asthma." CHEST Journal 2003;124(4): 1318-1324.

24. Burrows, B, Lebowitz, MD, Barbee, RA, et al Findings before diagnosis of asthma among the elderly in a longitudinal study of a general population sample. J Allergy Clin Immunol1991; 88:870-877.

\begin{tabular}{|c|l|l|l|}
\hline \multicolumn{3}{|c|}{ AUTHORSHIP AND CONTRIBUTION DECLARATION } \\
\hline Sr. \# & \multicolumn{1}{|c|}{ Author-s Full Name } & \multicolumn{1}{c|}{ Contribution to the paper } & Author=s Signature \\
\hline 1 & Syed Hafeezul Hassan & Principal author \\
\hline 2 & Javeria Rehman & $\begin{array}{l}\text { Data analysis, Interpretation } \\
\text { and manuscript writing } \\
\text { Proof reading and } \\
\text { manuscript writing }\end{array}$ \\
\hline 3 & Ahsan Ashfaq & \\
\hline
\end{tabular}

